\title{
Menggambar Kartun Tematik pada Guru-Guru PAUD/Taman Kanak-Kanak di Kota Makassar
}

\author{
Karta Jayadi $^{1}$, Arifin Manggau ${ }^{2}$ \\ ${ }^{1}$ Fakultas Seni dan Desain, Universitas Negeri Makassar \\ ${ }^{2}$ Fakultas Ilmu Pendidikan, Universitas Negeri Makassar
}

\begin{abstract}
The purpose of this program is how kindergarten teachers can recognize, understand and be able to draw thematic cartoons. The identification of problems that are often encountered in kindergarten especially in Makassar City is the lack of ability of kindergarten teachers in understanding and skillfully making thematic cartoons. Some related activities include: 1) Identification of thematic cartoons and their types for the kindergarten children category in Makassar City, 2) Introduction of thematic cartoons for teachers for kindergarten children in the form of performance, and, 3) The presentation form of the thematic cartoon which drew by teachers for kindergarten children. The results of this program, are: 1) The number of kindergarten teachers who have recognized and understood the types and forms of thematic cartoons for early childhood. There are funny cartoons, humorous cartoons, as well as criticism cartoons, 2) The teacher has been able to know the technique of drawing thematic cartoons in the form of performance. It has produced cartoons from funny pictures to critical ones. 3) The teacher is skilled at presenting thematic cartoons in a simple way.
\end{abstract}

Keywords: drawing, thematic cartoons, teachers, parents/kindergarten

\section{PENDAHULUAN}

Widia Pekerti dkk. (2012) menyatakan Seni rupa adalah kegiatan menciptakan atau kegiatan berkreasi terhadap pengalaman yang pernah terjadi. Seni rupa atau visual art juga sebagai bentuk ungkapan seni yang mengekspresikan pengalaman hidup, peristiwa yang terjadi, pengalaman estetik atau artistik manusia dengan diungkapkan melalui unsur seni (seni rupa, gerak, bunyi dan bahasa). Karya seni rupa dapat diklasifikasikan berdasarkan bentuk dan dimensinya adalah dua dimensi (dwimarta) dan tiga dimensi (trimatra). Hajar Pamadi (2012) menjelaskan bahwa hakekat seni rupa bagi anak TK ada 4 macam sebagai berikut: 1) seni sebagai bahasa, 2) seni membantu pertumbuhan mental, 3) nilai korelasi pelajaran seni membantu terhadap bidang yang lain, dan 4) seni sebagai media bermain.

Perilaku anak tidak dapat lepas dari kegiatan kesenian, karena dari sini setiap anak dapat mengungkapkan ide gagasan, imajinasi, sebuah peristiwa yang pernah terjadi melalui karya seni misal melukis, menggambar, menyanyi, dan tari. Kegiatan ini sebagai sarana komunikasi anak secara visual. Dalam proses berkarya seni, pikiran dan perasaan anak akan bercampur secara aktif. Anak usia dini atau TK belum dapat membedakan makan berfikir dan merasakan semuanya masih menyatu dalam kegiatan yang bersifat refleksi. Viktor Lowenfeld dan Lambert Britain (Hajar Pamadi, 2012) pernah mengutarakan bahwa karya seni anak ini mempunyai jangkuan pikiran yang sangat komprehensif, sering cara menyimbolkan ide dan gagasan serta perasaan anak yang tidak dimengerti oleh orang dewasa tidak direspon secara positif, sehingga anak kendur dalam mengembangkannya.

Bentuk yang dirasakan, dibayangkan, dan dipikirkan oleh seorang anak dalam bentuk karya seni, bentuk semacam ini hadir bersamaan dengan perkembangan usia mental anak. Pandangan humanistik perkembangan anak dipengaruhi oleh faktor lingkungan dan faktor internal. Keduanya berjalan saling mempengaruhi secara seimbang. Ketika berkarya seni, anak akan dikoordinasi oleh otak. Otak akan bekerja sendiri karena ada dorongan dari mata. Gerakan mata selama belajar dan berfikir terikat pada modalitas visual, auditonal, dan kinestetik. Dengan kata lain, mata 
bergerak menurut cara otak mengakses informasi. Pembelajaran karya seni rupa adalah belajar memahami sekeliling melalui latihan daya ingat. Kerja otak dapat menyimpan dan menciptakan citra visual dan kinerja mata bergerak ke informasi yang tersimpan untuk diciptakan.

Mendidik anak kita harus dapat mengembangkan kecerdasan majemuk. Kecerdasan akan disisipkan dalam mata pelajaran agar semua berkembang secara beriringan berdasarkan kemampuan anak. Anak harus mampu menangkap semua obyek dengan menelaah secara komperhensif semua mata pelajaran dan dapat dituangkan dalam karya seni menggambar atau melukis. Kegiatan mentransfer bentuk, peristiwa atau sebuah nilai obyek diubah menjadi gambar, sedangkan kegiatan mengamati obyek benda disekitar kita tentang perilaku manusia, proses ini disebut transfer. Peristiwa belajar seni dapat melatih kreativitas, kecakapan dapat digunakan dalam memecahkan masalah dalam materi dengan keuletannya dapat mempermudah untuk memecahkan masalah.

Manusia tidak akan lepas dalam bermain, karena melalui bermain pengalaman yang didapat begitu luas, mulai berimajinasi, pikiran dan perasaan anak bergerak untuk bereksplorasi dengan alam sekitar. Bermain sebagai modal untuk melatih imajinasi, pikiran, dan perasaan. Pendidikan seni rupa dalam penelitian ini adalah melalui seni anak dapat mengungkapkan sesuatu bentuk visual, melalui seni rupa anak dapat membantu perkembangan mental anak, pembelajaran seni dapat membantu pada bidang lain seperti dapat mengembangkan kreativitas anak. pembelajaran seni rupa dapat sebagai media bermain anak.

Widia Pekerti, dkk (2012) dalam karya seni rupa dua dimensi memiliki unsur visual yang dapat mempengaruhi karya seni rupa menjadi indah dan dapat dinikmati. Ada 8 unsur seni rupa adalah titik dan bintik, garis, bidang, bentuk, warna, tekstur, gelap terang, ruang, dan cahaya.

Garis merupakan coretan, torehan dengan cara menggores dengan benda tajam, baik menggunakan pewarna, atau pensil. Benda dan warna yang digoreskan menyatu dengan yang lain. Garis dibagi dua macam garis formal dengan penggaris dan garis bebas berupa goresan langsung dengan tangan atau benda tajam.

Bentuk ada 2 pengertian tiga dimensi dan dua dimensi. Pengertian dari tiga dimensi unsur seni rupa terbentuk dari ruang atau volume, sedangkan pengertian dari dua dimensi sebuah bentuk yang bergambar tidak bervolume. Jenis bentuk ada 2 macam yaitu (a) bentuk geometri adalah bentuk yang dibuat menggunakan penggaris seperti segitiga, persegi, persegi pajang, dan lingkaran (b) bentuk bebas atau informal adalah menggoreskan langsung dengan cara disusun, dipahat, dipijit, atau digoreskan langsung menggunakan tangan.

Suatu wujud keindahan seni rupa terlihat dari unsur seni rupa yang berupa warna. Ditinjau dari ilmu kimia warna merupakan unsur seni rupa yang terbuat dari pigmen (zat warna). Secara ilmu fisika merupakan pembiasaan cahaya pada prisma yang menimbulkan spektrum pelangi. Brewster (Widia Pekerti dkk., 2012) warna dikategorikan menjadi 3 macam yaitu warna primer, sekunder, dan tersier. Warna bagi anak mempunyai arti simbolik maupun arti ekspresi. Simbolis merupakan warna yang digunakan untuk menggambarkan isi perasaan anak, sedangkan warna ekspresi menggambarkan tentang kondisi anak. Warna bagi anak sebagai perwakilan atau simbol ungkapan perasaan tentang kesedihan, gembira, senang atau sekedar memenuhi ruang gambar.

Tekstur merupakan karakter permukaan suatu benda halus atau kasar. Secara visual dibedakan menjadi 2 macam yaitu tekstur nyata dan semu. Tekstur nyata jika dilihat dan diraba sama nilainya, sedangkan tekstur semu jika dilihat dan diraba nilainya beda.

Seperti halnya pada sketsa kartun, dimana pada mulanya adalah penamaan bagi sketsa pada kertas alot (stout paper) sebagai rancangan atau desain untuk lukisan kanvas atau lukisan dinding, gambar arsitektur, motif permadani, atau untuk gambar pada mozaik dan kaca. Namun seiring perkembangan waktu, pengertian kartun pada saat ini tidak sekadar sebagai sebuah gambar rancangan, tetapi kemudian berkembang menjadi gambar yang bersifat dan bertujuan humo (Suryaningrum dkk., 2005). Sebagai salah satu bentuk komunikasi 
grafis, kartun merupakan suatu gambar interpretatif yang menggunakan simbol untuk menyampaikan suatu pesan secara cepat dan ringkas, atau sesuatu sikap terhadap orang, situasi, atau kejadiankejadian tertentu. Kartun biasanya hanya mengungkap esensi pesan yang harus disampaikan dan menuangkannya ke dalam gambar sederhana, tanpa detail, dengan menggunakan simbol-simbol, serta karakter yang mudah dikenal dan dimengerti secara cepat. Menurut Suryaningrum dkk. (2005) kartun, seperti halnya monumen, ritus, film, dan advertensi merupakan bentuk komunikasi. Kartun biasanya diciptakan sebagai reaksi terhadap peristiwa fenomena tertentu sehingga memungkinkan digali atau dicari isi faktanya.

Hanya saja pada pembelajaran formal Taman Kanank-Kanak, yang dikenal sangat dekat dengan dunia kartun namun masih memiliki keterbatasan ketika menuangkan dalam sebuah gambar secara sedehana. Hal ini terkendala atas lemahnya peran pendidik dalam mengajarkan dan mengenalkan dunia kartun secara praktek menggambar kartun didalam kelas.

Berangkat dari hal tersebut diatas, sangat menarik untuk melakukan sebuah pelatihan di masyarakat terkhusus guru-guru TK/Paud di Kota Makassar sebagai upaya untuk memahamkan dan terampil tentang Menggambar Kartun Tematik untuk Taman Kanak-Kanak/Paud.

\section{METODE PELAKSANAAN}

Berdasarkan hasil identifikasi masalah yang sering dijumpai di Taman Kanak-Kanak khususnya di kota Makassar adalah kurangnya kemampuan guru Taman Kanak-Kanak dalam memahami dan terampil membuat gambar kartun bersifat tematik di kota Makassar. Beberapa kegiatan yang dilakukan sekaitan hal tersebut adalah:

a. Peningkatan pengetahuan pada guru-guru dalam mengidentifikasi gambar kartun tematik sekaitan pembelajaran di sekolah Taman Kanak-Kanak yang ada di Kota Makassar.

b. Peningkatan pengetahuan pada guru-guru Taman Kanak-Kanak atau PAUD dalam mengenalkan gambar kartun tematik untuk anak. c. Peningkatan pengetahuan pada guru-guru tentang bentuk penyajian gambar kartun tematik untuk anak Taman Kanak-Kanak di Sekolah.

Adapun Langkah yang dilakukan dalam pelaksanaan pelatihan tersebut, adalah sebagai berikut:

a. Pelaksanaan program dengan metode ceramah, diskusi, praktek atau unjuk kerja.

b. Penyusunan laporan

c. Seminar akhir

\section{HASIL DAN PEMBAHASAN}

Kegiatan ini dilaksanakan di kota Makassar propinsi Sulawesi Selatan dengan menghadirkan peserta yang meliputi guru-guru Taman KanakKanak dari berbagai asal sekolah. Salah satu media pembelajaran di Taman Kanak-Kanak adalah kegiatan menggambar. Kegiatan menggambar adalah media pembelajaran yang merupakan jenis pembelajaran yang banyak disukai oleh anak, yang tentunya selain mengembangkan kognitif anak, juga dapat mengembangkan bakat minat anak. Serta dalam kegiatan menggambar ini, terjangkau oleh semua anak untuk dilakukannya.

Pada dasarnya kegiatan menggambar di sekolah Taman Kanak-Kanak, umumnya adalah kegiatannya dalam pembelajaran menggambar bentuk dan mewarnai saja. Namun kegiatan menggambar kartun hanya lebih pada berupa tontonan video audio visual. Sehingga untuk terciptanya suatu kegiatan menggambar kartun seiring pembelajaran kegiatan menggambar di Taman Kanak-Kanak, tentunya selain menggambar bentu atau mewarnai, juga dilakukan permodelan baru dalam kegiatan menggambar yang lebih dengan pendekatan menggambar kartun.

Kegiatan menggambar kartun ini sesuai program yang ada tentunya. Dengan kegiatan menggambar kartun tematik, program yang dilakukan adalah membuat gambar kartun secara sederhana yang bersifat tematik. Seperti menggambar kartun kepala manusia dengan bertemakan diri sendiri, menggambar kartun dengan tema alam semesta, menggambar layang-layang dengan tema 
rekreasi, dan menggambar rumah dengan tema tempat tinggalku.

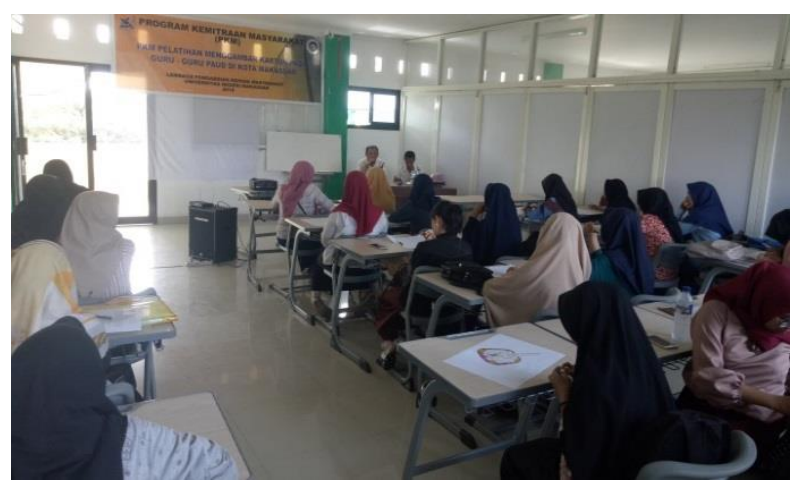

Gambar 1. Pembukaan pelatihan menggambar kartun bagi guru Taman Kanak-Kanak di Kota Makassar

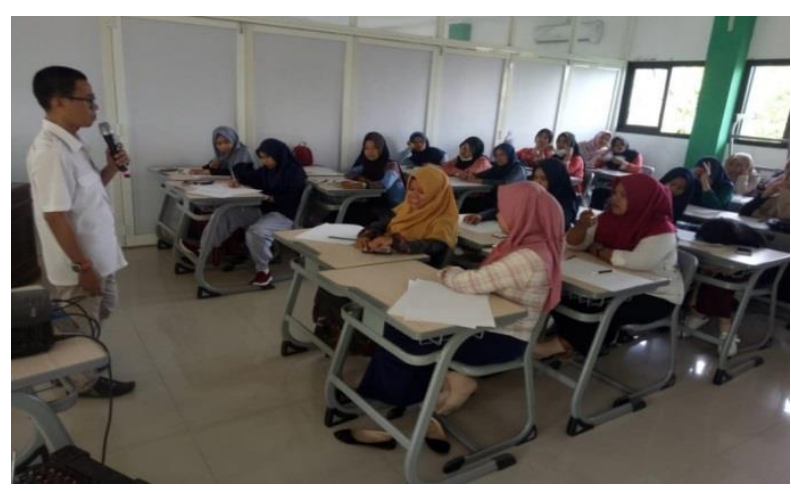

Gambar 2. Pelatihan menggambar kartun

Pemberian materi menggambar kartun pada peserta pelatihan. Materi ini menjelaskan tentang tatacara menarik garis dan membuat lengkungan garis. Kegiatan ini lebih pada pemberian pemahaman tentang jenis-jenis gambar kartun untuk anak Taman Kanak-Kanak.

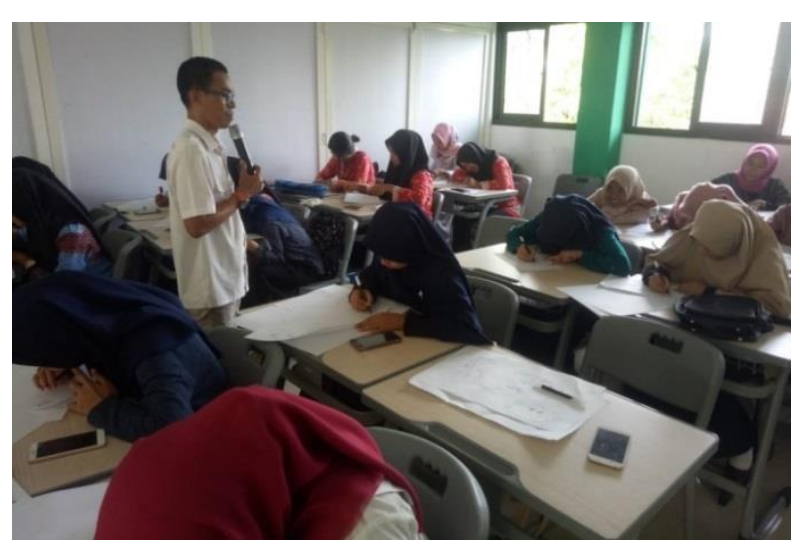

Gambar 3. Peserta menggambar kartun
Setelah peserta memahami tentang tatacara menggambar kartun, maka peserta sudah mulai menggambar sebagai bentuk uji coba atas materi yang telah di terima dari pemateri pelatihan menggambar kartun. Berikut adalah beberapa karyakarya peserta yang telah mereka hasilkan dengan berbagai bentuk gambar dengan tema-tema tertentu.

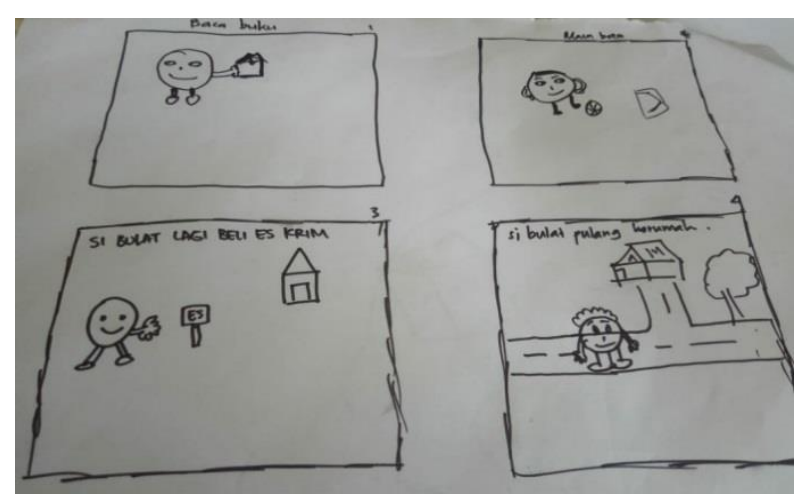

Gambar 4. Karya peserta gambar kartun Tema Tempat Tinggalku

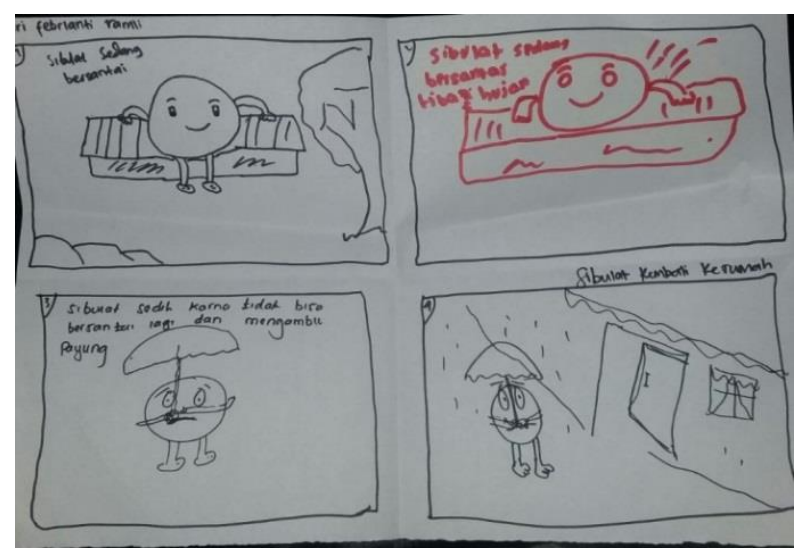

Gambar 5. Karya peserta gambar kartun Tema Alam Semesta

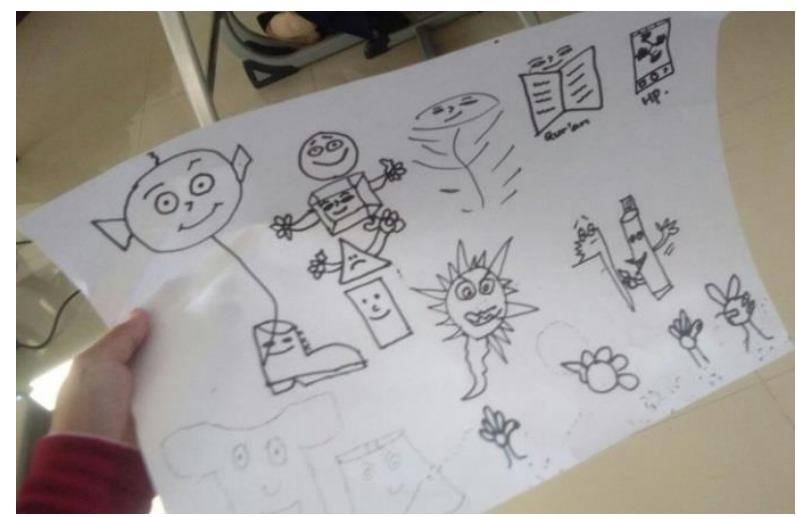

Gambar 6. Karya peserta gambar kartun Tema Diri Sendiri 


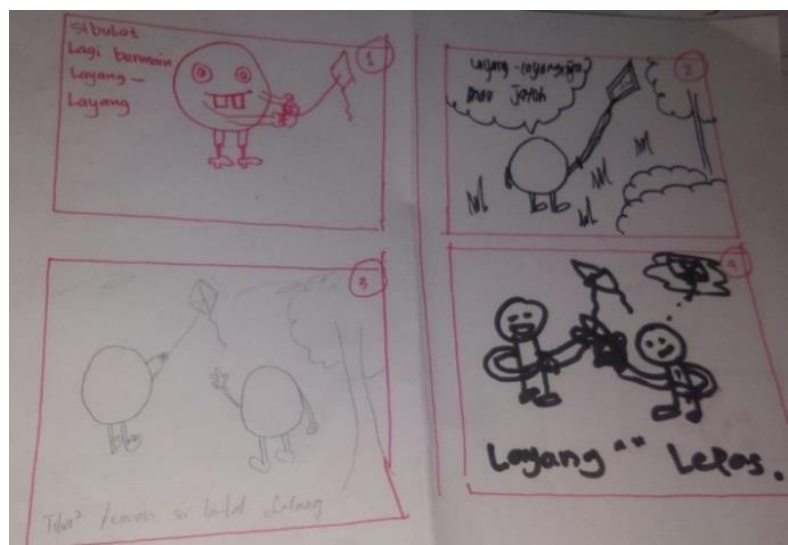

Gambar 7. Karya peserta gambar kartun Tema Rekreasi

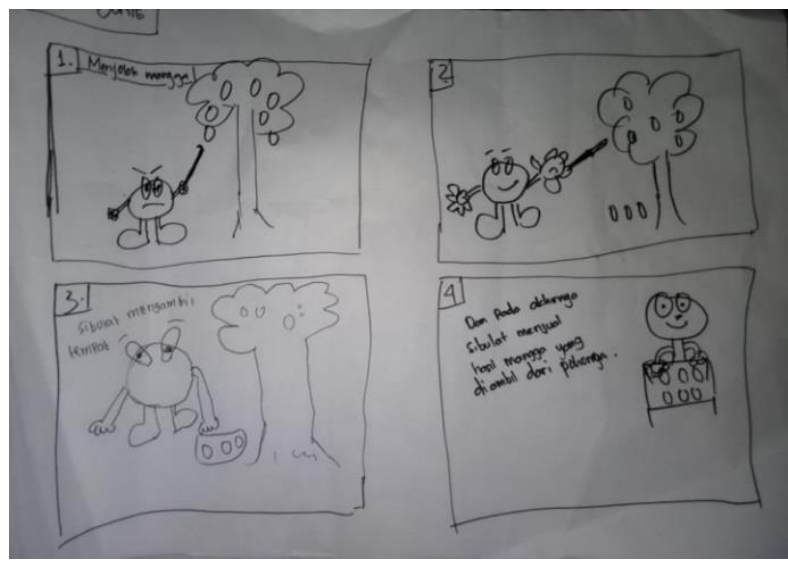

Gambar 8. Karya peserta gambar kartun Tema Tempat Tinggalku

Dengan demikian, setelah pelatihan menggambar kartun tematik telah terlaksana di kota Makassar, para peserta dapat memahami dan mampu menggambar kartun secara sederhana. Hal ini menandakan bahwa, kegiatan menggambar kartun di sekolah Taman Kanak-Kanak adalah hal yang mudah hanya saja selama ini terkendala dengan pengetahuan yang dimiliki para pendidik atau guru-guru di Taman Kanak-Kanak. Sehingga kedepan, pembelajaran kegiatan menggambar kartun, senantiasa dilakukan di sekolah-sekolah terkhusus Taman Kanak-Kanak dan PAUD.

\section{KESIMPULAN}

a. Pelaksanaan kegiatan menggambar kartun tepatnya di kota Makassar propinsi Sulawesi Selatan. Salah satu media pembelajaran di Taman Kanak-Kanak adalah kegiatan menggambar. Kegiatan menggambar adalah media pembelajaran yang merupakan jenis pembelajaran yang banyak disukai oleh anak, yang tentunya selain mengembangkan kognitif anak, juga dapat mengembangkan bakat minat anak. Serta dalam kegiatan menggambar ini, terjangkau oleh semua anak untuk dilakukannya.

b. Pada dasarnya kegiatan menggambar di sekolah Taman Kanak-Kanak, umumnya adalah kegiatannya dalam pembelajaran menggambar bentuk dan mewarnai saja. Namun kegiatan menggambar kartun hanya lebih pada berupa tontonan video audio visual. Sehingga untuk terciptanya suatu kegiatan menggambar kartun seiring pembelajaran kegiatan menggambar di Taman Kanak-Kanak, tentunya selain menggambar bentu atau mewarnai, juga dilakukan permodelan baru dalam kegiatan menggambar yang lebih dengan pendekatan menggambar kartun.

c. Dengan kegiatan menggambar kartun tematik, program yang dilakukan adalah membuat gambar kartun secara sederhana yang bersifat tematik. Seperti menggambar kartun kepala manusia dengan bertemakan diri sendiri, menggambar kartun dengan tema alam semesta, menggambar layang-layang dengan tema rekreasi, dan menggambar rumah dengan tema tempat tinggalku.

\section{UCAPAN TERIMA KASIH}

Ucapan Terimakasih kepada Bapak Rektor Universitas Negeri Makassar yang telah memberi izin pengabdian, kepada Ketua Lembaga Pengabdian Masyarakat UNM dan Pemerintah Kota Makassar Propinsi Sulawesi Selatan.

\section{DAFTAR PUSTAKA}

Pekerti, Widia dkk. 2012. Metode Pengembangan Seni. Jakarta: Universitas Terbuka.

Hajar Pamadhi, 2012, Pendidikan Seni: Hakikat, kurikulum Pendidikan Seni, Habitus Seni dan Pengajaran Seni Untuk Anak, UNY Press, Yogyakarta.

Suryaningrum, Th. Dwi, J. Basmal, dan Nurochmawati. 2005. Studi pembuatan edible film dari karaginan. Jurnal Penelitian Perikanan Indonesia. 11(4): 1-14. 